\title{
ANTIOXIDANT POTENTIAL AND SIMULTANEOUS ESTIMATION OF QUERCETIN, RUTIN, AND GALLIC ACID IN CURCUMA SPECIES
}

\author{
SOWMYA PRIYA ${ }^{1}{ }^{1}$, SANGILIMUTHU A ${ }^{1 *}$, KARPAGAVALLI $M^{2}$, RAMKUMAR M $^{1}$, JOSPHIN NIRMALA A $^{1}$
}

${ }^{1}$ Department of Biotechnology, Karpagam Academy of Higher Education, Coimbatore - 641 021, Tamil Nadu, India. ${ }^{2}$ Department of Pharmaceutical Chemistry, Karpagam College of Pharmacy, Coimbatore - 641032. Tamil Nadu, India. Email: smuthu.al@gmail.com

Received: 14 July 2017, Revised and Accepted: 04 October 2017

\section{ABSTRACT}

Objective: This study was designed to provide simple and cost-effective methods to quantify the biologically active phytoconstituents such as rutin, quercetin, and gallic acid from Curcuma species and evaluation of the antioxidant potential of different parts with different solvent extracts of Curcuma species.

Methods: Ultraviolet-visible spectrophotometer was used for the analysis of quercetin, rutin, gallic acid and total flavonoid content of Curcuma species extracts. Antioxidant potential of Curcuma species extracts were evaluated using 2-2-diphenyl-1-picrylhydrazyl (DPPH) free radical scavenging activity.

Results: Ethyl acetate extract of Curcuma aromatica rhizome, aerial part contain higher quantity of quercetin and rutin compared to the other extracts, and also Curcuma species such as Curcuma longa and Curcuma amada contains high antioxidant capacity. The total flavonoid content was high in ethyl acetate extract of Curcuma aromatica as $88.35 \pm 0.25 \mu \mathrm{g} / \mathrm{g}$ dry weight of quercetin equivalents.

Conclusion: Different extracts of Curcuma species possess good free radical scavenging activity and the IC ${ }_{50}$ of Curcuma amada aerial part, Curcuma longa aerial part, and Curcuma aromatica rhizome was $61.65 \pm 1.75,62.95 \pm 1.85$, and $89.40 \pm 0.15$ ( $\mu$ g/ml), respectively. The Curcuma species contains high total flavonoid content and antioxidant potential.

Keywords: Curcuma aromatica, Curcuma longa, Curcuma amada, Rutin, Quercetin.

(C) 2017 The Authors. Published by Innovare Academic Sciences Pvt Ltd. This is an open access article under the CC BY license (http://creativecommons. org/licenses/by/4. 0/) DOI: http://dx.doi.org/10.22159/ajpcr.2017.v10i12.14093

\section{INTRODUCTION}

Curcuma is a major genus in the family of Zingiberaceae and it contains nearly 100 species [1]. It is a rhizomatous herb distributed throughout the world; most of the species are present in China. Curcuma species being used as traditional medicine for various diseases in developing countries among the traditional healers and also used as traditional Chinese medicine for various illness among the Chinese communities. The Curcuma species has been traditionally used in India for several human illnesses. In Curcuma species, Curcuma longa rhizome powder has been used for cough, wound healing from the ancient time. Among the scientific communities, various parts of $C$. longa have been proved to have an antioxidant [2], antibacterial [3], anticancer [4], hepatoprotective effects [5], and anti-inflammatory [6] potentials due to the presence of major bioactive principles such as $\alpha$-turmerone and $\beta$-turmerone in essential oil extracted from $C$. longa rhizome [2], and it contains curcumin, demethoxycurcumin, and bisdemethoxycurcumin identified with high-performance liquid chromatography coupled with electrochemical detection methods [7]. Different organic solvents such as petroleum ether, chloroform, benzene, methanol, and aqueous fractions of $C$. longa demonstrated against Staphylococcus aureus found that petroleum ether and methanol fractions possess higher antimicrobial activity [8]. The essential oil extracted from C. longa leaves and it acts as potential candidate for the oxidative mediated damage by in vitro 2-2-diphenyl-1-picrylhydrazyl (DPPH) and ABTS free radical scavenging methods [9]. Another major species from the genus of Curcuma is Curcuma aromatica and Curcuma amada which have various pharmaceutical applications. Essential oil from C. aromatica is very active against various free radicals [10] and contains camphor, vinyldimethylcarbinol, bomeol, and cubenol. Potent larvicidal compounds as 9-oxoneoprocurcumenol and neoprocurcumenol from petroleum ether extract of $C$. aromatica against mosquito larvae [11] and also, ethyl acetate extract of $C$. aromatica rhizome contains curcumin, demethoxycurcumin, and $\beta$-sitosterol-3-0-b-D-glucopyranoside [12]. The methanol extract of $C$. amada leaves and rhizome has shown good anticancer potentials against MCF-7 cell lines [13]. The chloroform extract of $C$. amada rhizome contains amadannulen and crude extract possesses antioxidant activity on DPPH, superoxide, lipid peroxidation, and antibacterial activity against Micrococcus luteus, Bacillus cereus, and Bacillus subtilis [14,15].

The rhizomes of $C$. longa, $C$. aromatica, and $C$. amada are used as traditional medicine and food. However, it is difficult to distinguish their pharmacological activities as their chemical characteristics are obviously different. Therefore, quantitative analysis of chemical characteristics such as quercetin, gallic acid, and rutin is very important for ensuring the efficacy of the herbs. Mostly, after harvesting the rhizomatous part of the Curcuma species, the aerial part burned in their vegetation field as waste to avoid that, there should be attempts to quantify the pharmaceutical important biomolecules in useful manner using simple and cost-effective methods such as ultraviolet (UV)-visible spectrophotometer and Fourier transform infrared spectroscopy.

Quercetin is a flavonol found in many plants and it is used as an ingredient in various food preparations. Quercetin is synthesized in plants by phenylpropanoid biosynthetic pathway with key enzymes such as phenylalanine ammonia-lyase, cinnamate-4-hydroxylase, and 4-coumaroyl-CoA ligase. It is used for treating high cholesterol, heart disease, diabetes, cataracts, hay fever, peptic ulcer, schizophrenia, inflammation, asthma, gout, viral infections, chronic fatigue syndrome, preventing cancer, and for treating chronic infections of the prostate [16]. Rutin is the glycoside between the flavonol quercetin 
and the disaccharide rutinose, and also it is one of the phenolic compounds found in various medicinal plants. Rutin was first isolated from Ruta graveolens which is the source of the name. It inhibits the platelet aggregation [17] and decreases capillary permeability, improving blood circulation, anti-inflammatory activity, and it inhibit aldose reductase $[18,19]$. Gallic acid is a type of phenolic acid and it is formed from 3-dehydroshikimate with shikimate dehydrogenase to produce 3,5-didehydroshikimate of tautomerizes to form the gallic acid [20], and it is found in a number of plants containing high antioxidant activity.

Antioxidants have been widely used as additive to provide protection against oxidative degradation of foods [21]. Although many synthetic chemicals such as flavonoids, phenolic compounds are found to be strong radical scavengers and also, these compounds have serious side effects [22]. In this context, attempts to quantify the quercetin, rutin, and gallic acid in different solvent extract of C. longa, C. aromatica, and $C$. amada aerial parts and rhizomatous parts and revealed the free radical scavenging abilities of the extracts as natural sources are important.

The objective of our work was to assess and compare the phytochemical components and antioxidant properties of different solvent extracts of Curcuma species aerial parts and rhizomatous parts of C. longa $\mathrm{L}$. (turmeric), C. amada Roxb (mango-ginger), and C. aromatica Salisb (wild turmeric).

\section{METHODS}

\section{Collection of the plant samples}

The C. longa, C. amada, and C. aromatica species were collected at the Tamil Nadu Agriculture University, Coimbatore, from November 2014 to January 2015, and the species were identified and authenticated by the Botanical Survey of India, Coimbatore - 641 003, Tamil Nadu, India, and the voucher specimen was deposited at the same institute for future reference.

\section{Chemicals}

Petroleum ether, chloroform, ethyl acetate, methanol, ethanol, gallic acid (Himedia), quercetin (Himedia), rutin (Himedia), aluminum chloride, potassium acetate, and DPPH were used, and all the chemicals including the solvents were of analytical grade.

\section{Extract preparation}

The collected plant materials (aerial part and rhizome) were washed thoroughly in tap water, chopped, air dried for $1-2$ weeks at $35-40^{\circ} \mathrm{C}$, and pulverized in an electric grinder. The $50 \mathrm{~g}$ dry plant materials were taken for sequential extraction with increasing polarity of the solvents (petroleum ether, chloroform, ethyl acetate, and methanol) finally concentrated to get powdered for further quantified and antioxidant studies were carried out [23]

UV-visible spectrophotometer analysis of quercetin, rutin, and gallic acid

The major phytochemicals were screened with respective standard compounds such quercetin, rutin, and gallic acid using UV-visible spectrophotometer of Curcuma extracts. Preprepared defatted ethyl acetate, chloroform, and methanol extracts of C. longa, C. amada, and C. aromatica aerial parts and rhizomes were taken for this analysis and dissolved with respective solvents and the maximum absorbance bands compared with that of standard compounds.

\section{Estimation of total flavonoid content}

The content of total flavonoid in the ethyl acetate, chloroform, and methanolic extracts of C. longa, C. aromatica, and C. amada aerial part and rhizome was assessed [24]. 1 milliliter of each extract was mixed with $0.5 \mathrm{ml}$ of $2 \%$ aluminum chloride ethanol solution. After $1 \mathrm{hr}$ incubation at room temperature, the absorbance was measured at $415 \mathrm{~nm}$. A yellow color indicated the presence of flavonoid. The total flavonoid content was calculated as quercetin equivalent (mg GE/g).

\section{Antioxidant activity}

\section{DPPH radical scavenging activity}

The ability of ethyl acetate, chloroform, and methanolic extracts of C. longa, C. aromatica, C. amada aerial part and rhizome extracts to scavenge DPPH radicals was assessed according to a method described earlier with slight modifications [25]. Briefly, aliquots of the extract $100-500 \mu \mathrm{g} / \mathrm{ml}$ were mixed with $3.0 \mathrm{~mL}$ DPPH $(0.5 \mathrm{mmol} / \mathrm{L}$ in methanol), the resulting absorbance was recorded at $517 \mathrm{~nm}$ after 30 minutes incubation at $37^{\circ} \mathrm{C}$. The percentage of scavenging activity was derived using the following formula, Percentage of inhibition (\%)

$=\left[\left(\mathrm{A}_{\text {control }}-\mathrm{A}_{\text {sample }}\right) / \mathrm{A}_{\text {control }}\right] \times 100$

Where $\mathrm{A}_{\text {control }}$-absorbance of DPPH

$\mathrm{A}_{\text {sample }}$ - absorbance of reaction mixture (DPPH with Sample).

\section{RESULT AND DISCUSSION}

Estimation of total flavonoid content

After evaporation of solvents, the final concentrated extracts were diluted with respective solvents $(\mathrm{mg} / \mathrm{ml})$ and taken for total flavonoid analysis with quercetin equivalence. Aliquoted the quercetin $(20,40$, 60,80 , and $100 \mu \mathrm{g} / \mathrm{ml}$ ) and plotted regression calibration curve found which was $\mathrm{Y}=0.7245 \mathrm{x}-0.7641 \mathrm{R}^{2}=0.9857$ (Fig. 1). Different extract of C. longa, C. amada, and C. aromatic aerial parts and rhizome revealed their total flavonoid contents and high amount of flavonoid content was present in ethyl acetate extract of $C$. aromatica rhizome when compared to other extracts. Rhizome extracts contain more flavonoid content than aerial parts extracts (Table 1 ).

The total flavonoid content were presents in the selected Curcuma species in the following order: $C$. aromatic rhizome $>$ C. aromatic aerial part $>$ C. amada rhizome $>C$. amada aerial part $>C$. longa rhizome $>$ C. longa aerial part [26]. Compared to all the extracts C. aromatica rhizome contains more flavonoid contents. Flavonoids are one of the most diverse and widespread groups of natural compound contains antioxidants, anticancer, antidiabetic, antiaging, and these compounds prevent cardiovascular disease.

\section{UV-visible spectrophotometer analysis of quercetin, rutin and} gallic acid

The quercetin, rutin, and gallic acid were dissolved in methanol and screened their maximum absorbance peak $(\lambda \max )$ values of the substances using UV-visible spectral studies and found to be $375 \mathrm{~nm}, 257 \mathrm{~nm}$, and 310 $\mathrm{nm}$, respectively. Same manner preprepared ethyl acetate, chloroform, and methanol extracts of $C$. longa, C. amada, and C. aromatica aerial parts and rhizomes were dissolved in respective solvents and performed full-length scan against blank between 200 and $800 \mathrm{~nm}$ and observed the maximum absorbance peak of the extracts. The absorbance values $(\lambda \max )$ were compared to the standard quercetin, rutin, and gallic acid.

Fig. 2 shows the absorbance bandwidth of the ethyl acetate extract of Curcuma species aerial part and rhizomatous parts found to be C. aromatica rhizome ethyl acetate extract (CA2REA), C. aromatica

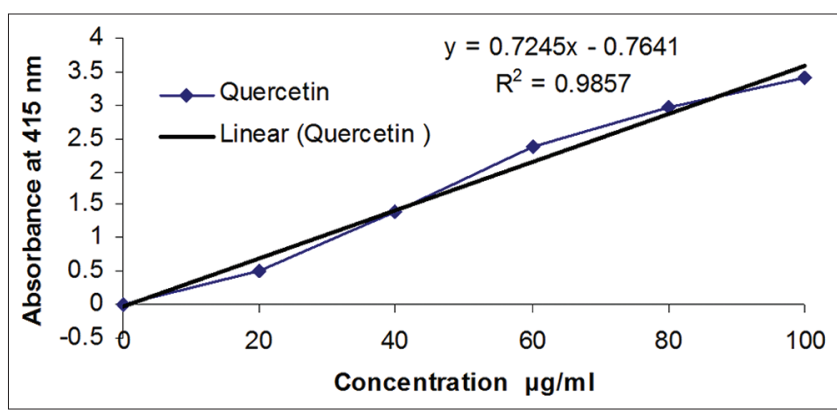

Fig. 1: Total flavonoid content with quercetin equivalent 
aerial part ethyl acetate extract (CA2AEA), and C. amada aerial part ethyl acetate extract (CA1AEA) contains strong peak values were nearby the quercetin and rutin $\lambda$ max, it shows these two substances present in the crude extracts. C. longa rhizome ethyl acetate extract (CLREA), C. longa aerial part ethyl acetate extract (CLAEA) contains weakest peak values were nearby the quercetin and rutin $\lambda$ max, it shows these two substances present in the extracts with lower concentration.

Fig. 3 shows the chloroform extract of Curcuma species was screened with UV-visible spectrophotometer and the absorbance peak values

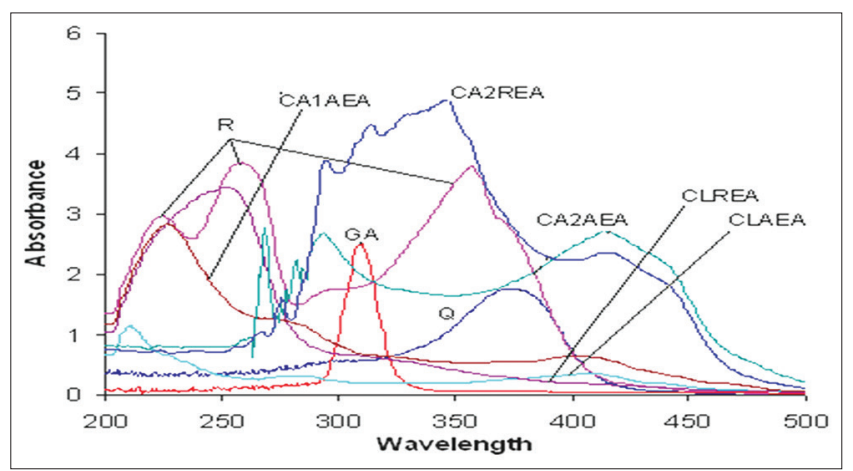

Fig. 2: Ultraviolet-visible spectra of ethyl acetate extracts of Curcuma sp.

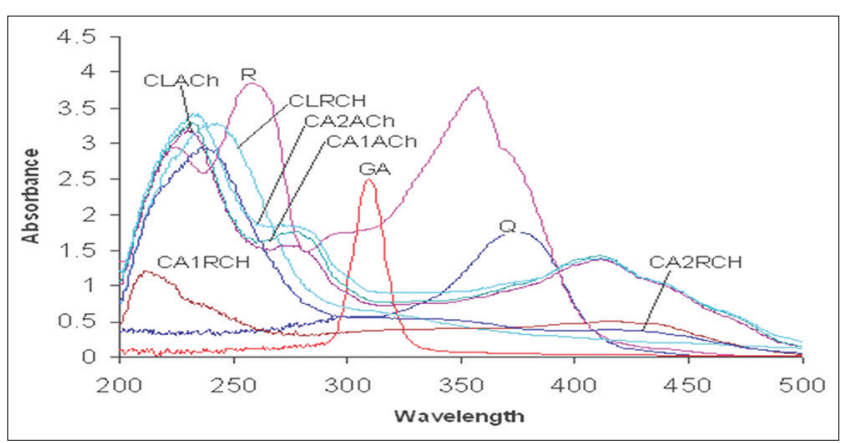

Fig. 3: Ultraviolet-visible spectra of chloroform extracts of Curcuma sp. compared to the quercetin, rutin, and gallic acid UV-visible spectra. The result shows $C$. longa aerial part chloroform extract (CLACh), C. aromatic aerial part chloroform extract (CA2Ach), and C. amada aerial part chloroform extract (CA1Ach) absorbance band exactly match with rutin UV-visible spectra.

Fig. 4 shows, C. aromatica rhizome methanol extract (CA2RM), C. aromatica aerial part methanol extract (CA2AM) UV-visible spectra possess more similar absorbance band to rutin and quercetin, it shows extract contains rutin and quercetin and rest of the UV-visible spectra of extracts show the lowest absorbance values in the respective standard band area.

\section{Antioxidant activity}

DPPH radical scavenging activity

The photometric evaluation of the antioxidant capacity of defatted ethyl acetate, chloroform, methanolic extracts of $C$. longa, C. aromatica, and C. amada aerial part and rhizome showed good antioxidant capacity (Fig. 5). Significant decreases were observed in preprepared DPPH radical due to the scavenging ability of the extracts [27]. The ability of DPPH radical scavenging is higher in C. aromatica rhizome ethyl acetate extract compared to other extracts.

The DPPH free radical scavenging activity of Curcuma species possess ability to scavenge DPPH free radicals as equal to the standard antioxidant L-ascorbic acid [30]. It produced hydrazine by converting

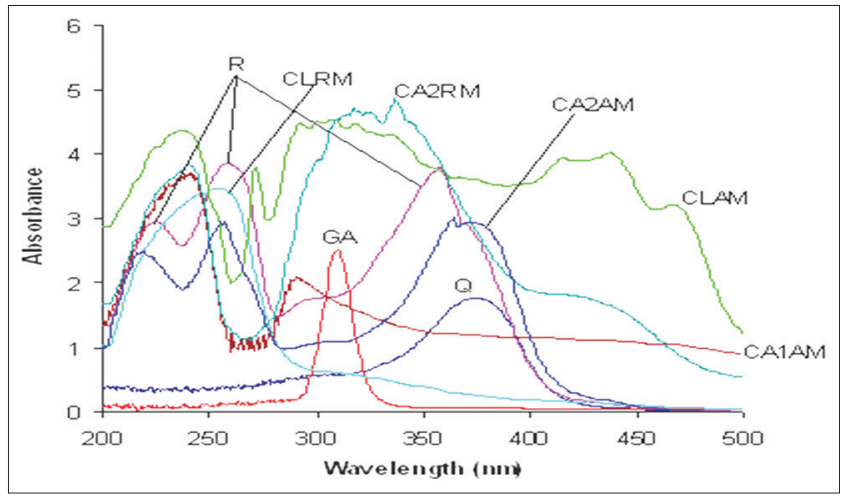

Fig. 4: Ultraviolet-visible spectra of methanol extracts of Curcuma sp.

Table 1: Total flavonoid contents of Curcuma species with quercetin equivalence

\begin{tabular}{lllll}
\hline S.No. & Plant materials & Solvents used for extraction & & \\
\cline { 3 - 5 } & & Ethyl acetate $\boldsymbol{\mu g} / \mathbf{m g}$ dry weight & Chloroform $\boldsymbol{\mu g} / \mathbf{m g}$ dry weight & Methanol $\boldsymbol{\mu g} / \mathbf{m g}$ dry weight \\
\hline 1 & Curcuma longa rhizome & $24.15 \pm 1.25$ & $6.15 \pm 0.12$ & $46.15 \pm 1.25$ \\
2 & Curcuma amada rhizome & $69.75 \pm 1.95$ & $10.15 \pm 0.95$ & $69.25 \pm 2.15$ \\
3 & Curcuma aromatica rhizome & $\mathbf{8 8 . 3 5} \pm \mathbf{0 . 2 5}$ & $\mathbf{1 7 . 2 2} \pm \mathbf{1 . 0 5}$ & $\mathbf{7 5 . 2 5} \pm \mathbf{0 . 9 5}$ \\
4 & Curcuma longa aerial part & $25.55 \pm 0.75$ & $1.25 \pm 0.05$ & $4.15 \pm 0.15$ \\
5 & Curcuma amada aerial part & $31.30 \pm 1.65$ & $7.45 \pm 0.15$ & $38.25 \pm 2.95$ \\
6 & Curcuma aromatica aerial part & $84.00 \pm 1.85$ & $12.35 \pm 0.65$ & $14.05 \pm 1.65$ \\
\hline
\end{tabular}

Table 2: IC $\mathrm{I}_{50}$ values of Curcuma species extracts with DPPH free radical scavenging activity

\begin{tabular}{lllll}
\hline \multirow{2}{*}{ S.No. } & Plant materials & $\mathbf{I C}_{\mathbf{5 0}}$ values & & \\
\cline { 3 - 5 } & & $\mathbf{E t h y l ~ a c e t a t e ~ e x t r a c t ~}(\boldsymbol{\mu g} / \mathbf{m l})$ & Chloroform extract $(\boldsymbol{\mu g} / \mathbf{m l})$ & Methanol extract $(\boldsymbol{\mu g} / \mathbf{m l})$ \\
\hline 1 & Curcuma longa rhizome & $300.15 \pm 1.85$ & $391.15 \pm 1.15$ & $415.55 \pm 1.45$ \\
2 & Curcuma amada rhizome & $91.15 \pm 1.15$ & $231.25 \pm 1.25$ & $275.13 \pm 2.10$ \\
3 & Curcuma aromatica rhizome & $\mathbf{8 9 . 4 0 \pm 0 . 1 5}$ & $>500$ & $92.35 \pm 1.75$ \\
4 & Curcuma longa aerial part & $\mathbf{6 2 . 9 5} \pm \mathbf{1 . 8 5}$ & $381.18 \pm 1.55$ & $>500$ \\
5 & Curcuma amada aerial part & $\mathbf{6 1 . 6 5} \pm \mathbf{1 . 7 5}$ & $250.45 \pm 2.15$ & $410.25 \pm 1.25$ \\
6 & Curcuma aromatica aerial part & $>500$ & & $>500$ \\
7 & Standard L-ascorbic acid & $61.15 \pm 1.25$ & & \\
\hline
\end{tabular}

DPPH: 2-2-diphenyl-1-picrylhydrazyl 


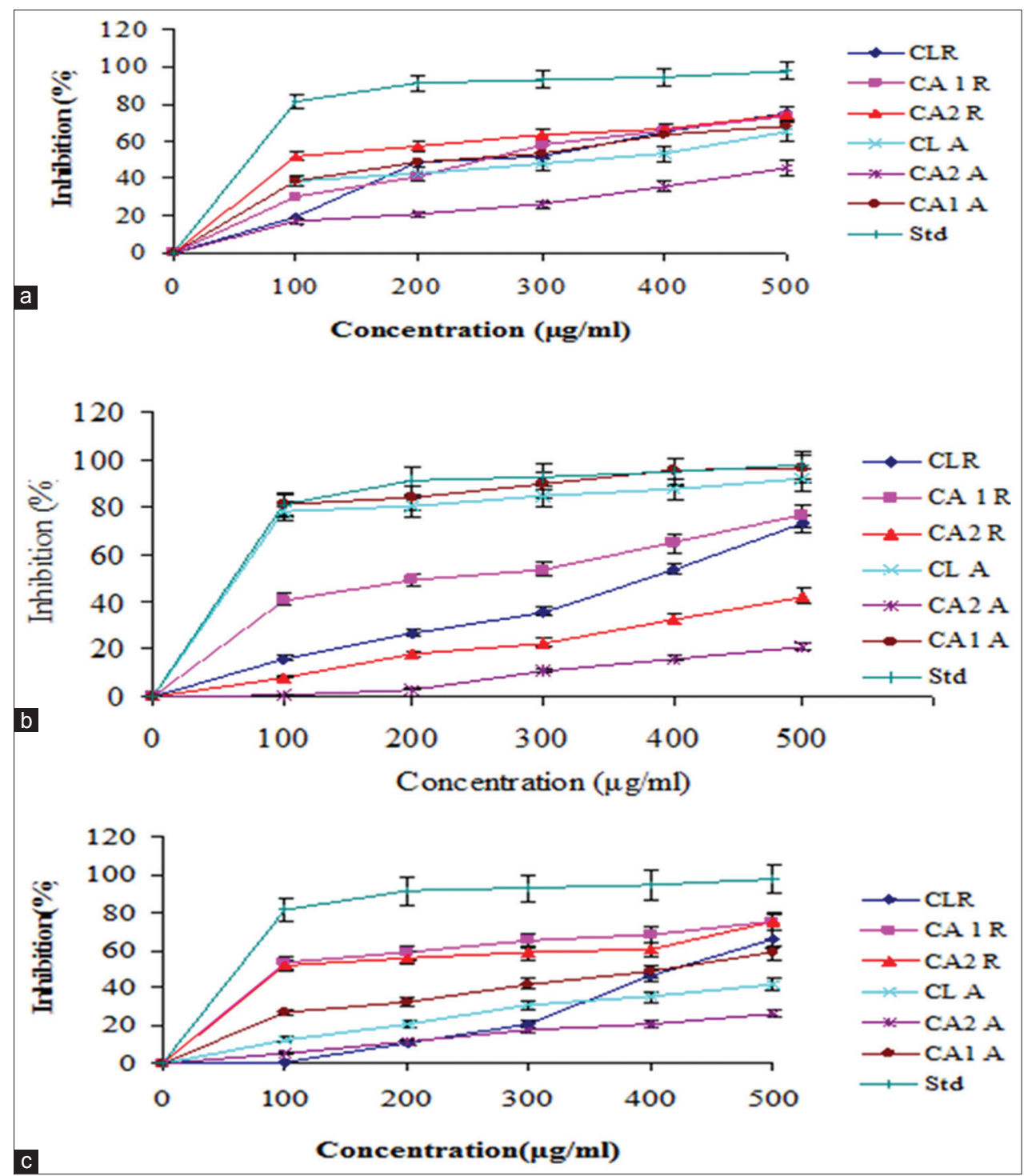

Fig. 5: 2-2-diphenyl-1-picrylhydrazyl free radical scavenging activity of Curcuma species (a) ethyl acetate extract, (b) chloroform extract, and (c) methanol extract. (Curcuma longa rhizome [CLR], Curcuma amada rhizome [CL1R], Curcuma. aromatica rhizome [CA2R], C. longa aerial part [CLA], C. amada aerial part [CA1A], and C. aromatica aerial part [CA1A])

the unpaired electrons to paired electron due to the hydrogen donating ability of the extract [28]. The $\mathrm{IC}_{50}$ values were shown in Table 2 and C. longa and C. amada extracts showed the $\mathrm{IC}_{50}$ values very nearer to the standard antioxidant L-ascorbic acid [29].

\section{CONCLUSION}

In conclusion, the total flavonoid contents and antioxidant potentials of de-fatted ethyl acetate, chloroform, and methanol extracts of Curcuma longa, Curcuma aromatica, Curcuma amada aerial parts and rhizome were revealed. Among the Curcuma species, $C$. aromatica rhizome - ethyl acetate extract was found to be an effective antioxidant with high total flavonoid contents. Ethyl acetate extract of $C$. aromatica rhizome and aerial part contains higher quantity of quercetin and rutin compared to the other extracts. Among the different solvent extracts of each parts, ethyl acetate extracts showed maximum total flavonoid content and high antioxidant capacity than the other extracts such as ethyl acetate $>$ methanol $>$ chloroform.

\section{ACKNOWLEDGMENT}

The authors gratefully acknowledge the authorities of Karpagam Academy of Higher Education, for providing financial assistance and necessary facilities to carry out this research work.

\section{REFERENCES}

1. Sasikumar B. Genetic resources of Curcuma: Diversity, characterization and utilization. Plant Genet Resour 2005;3(2):230-51.

2. Gounder DK, Lingamallu J. Comparison of chemical composition and antioxidant potential of volatile oil from fresh, dried and cured turmeric (Curcuma longa) rhizomes. Ind Crops Prod 2012;38:124-31.

3. Chan EW, Ng VP, Tan VV, Low YY. Antioxidant and antibacterial properties of Alpinia galanga, Curcuma longa, and Etlingera elatior (Zingiberaceae). Pharm J 2011;3(2):54-61.

4. Ramsewak RS, DeWitt DL, Nair MG. Cytotoxicity, antioxidant and anti-inflammatory activities of curcumins I-III from Curcuma longa. Phytomedicine 2000;7(4):303-8.

5. Kim Y, You Y, Yoon HG, Lee YH, Kim K, Lee J, et al. Hepatoprotective effects of fermented Curcuma longa $\mathrm{L}$. on carbon tetrachloride-induced oxidative stress in rats. Food Chem 2014;151:148-53.

6. Jurenka JS. Anti-inflammatory properties of curcumin, a major constituent of Curcuma longa: A review of preclinical and clinical research. Altern Med Rev 2009;14(2):141-53.

7. Long Y, Zhang W, Wang F, Chen Z. Simultaneous determination of three curcuminoids in Curcuma longa L. by high performance liquid chromatography coupled with electrochemical detection. J Pharm Anal 2014;4(5):325-30

8. Gupta A, Mahajan S, Sharma R. Evaluation of antimicrobial activity 
of Curcuma longa rhizome extract against Staphylococcus aureus. Biotechnol Rep (Amst) 2015;6:51-55.

9. Priya R, Prathapan A, Raghu KG, Menon AN. Chemical composition and in vitro ant oxidative potential of essential oil isolated from Curcuma longa L. leaves. Asian Pac J Trop Biomed 2012;2:S695-9.

10. Al-Reza SM, Rahman A, Sattar MA, Rahman MO, Fida HM. Essential oil composition and antioxidant activities of Curcuma aromatica Salisb. Food Chem Toxicol 2010;48(6):1757-60.

11. Madhu SK, Shaukath AK, Vijayan VA. Efficacy of bioactive compounds from Curcuma aromatica against mosquito larvae. Acta Trop 2010;113(1):7-11.

12. Awah FM, Uzoegwu PN, Oyugi JO, Rutherford J, Ifeonu P, Yao XJ, et al. Free radical scavenging activity and immunomodulatory effect of Stachytarpheta angustifolia leaf extract. Food Chem 2010;119(4):1409-16.

13. Jambunathan S, Bangarusamy D, Padma PR, Sundaravadivelu S. Cytotoxic activity of the methanolic extract of leaves and rhizomes of Curcuma amada Roxb against breast cancer cell lines. Asian Pac J Trop Med 2014;7S1:S405-9.

14. Policegoudra RS, Abiraj K, Channe Gowda D, Aradhya SM. Isolation and characterization of antioxidant and antibacterial compound from mango ginger (Curcuma amada Roxb.) rhizome. J Chromatogr B Analyt Technol Biomed Life Sci 2007;852(1-2):40-8.

15. Policegoudra RS, Aradhya SM. Biochemical changes and antioxidant activity of mango ginger (Curcuma amada Roxb.) rhizomes during postharvest storage at different temperatures. Postharvest Biol Technol 2007;46(2):189-94.

16. Winkel-Shirley B. Flavonoid biosynthesis. A colorful model for genetics, biochemistry, cell biology, and biotechnology. Plant Physiol 2001;126(2):485-93

17. Navarro-Núñez L, Lozano ML, Palomo M, Martínez C, Vicente V, Castillo $\mathrm{J}$, et al. Apigenin inhibits platelet adhesion and thrombus formation and synergizes with aspirin in the suppression of the arachidonic acid pathway. J Agric Food Chem 2008;56(6):2970-6.

18. Guardia T, Rotelli AE, Juarez AO, Pelzer LE. Anti-inflammatory properties of plant flavonoids. Effects of rutin, quercetin and hesperidin on adjuvant arthritis in rat. Farmaco 2001;56(9):683-7.

19. Jung CH, Lee JY, Cho CH, Kim CJ. Anti-asthmatic action of quercetin and rutin in conscious guinea-pigs challenged with aerosolized ovalbumin. Arch Pharm Res 2007;30(12):1599-607.

20. Dewick PM, Haslam E. Phenol biosynthesis in higher plants. Gallic acid. Biochem J 1969;113(3):537-42.

21. Gülçin I, Küfrevioglu OI, Oktay M, Büyükokuroglu ME. Antioxidant, antimicrobial, antiulcer and analgesic activities of nettle (Urtica dioica L.). J Ethnopharmacol 2004;90(2-3):205-15.

22. Imaida K, Fukushima S, Shirai T, Ohtani M, Nakanishi K, Ito N. Promoting activities of butylated hydroxyanisole and butylated hydroxytoluene on 2-stage urinary bladder carcinogenesis and inhibition of gamma-glutamyl transpeptidase-positive foci development in the liver of rats. Carcinogenesis 1983;4(7):895-9.

23. Yadav SA, Raj AJ, Sathishkumar R. In vitro antioxidant activity of Barleria noctiflora L. f. Asian Pac J Trop Biomed 2012;2:S716-22.

24. Marinova D, Ribarova F, Atanassova M. Total phenolics and total flavonoids in Bulgarian fruits and vegetables. J Univ Chem Technol Metall 2005;40(3):255-60.

25. Mondal SK, Chakraborty G, Gupta M, Mazumder UK. In vitro antioxidant activity of Diospyros malabarica Kostel bark. Indian J Exp Biol 2006;44(1):39-44.

26. Yadava SA, Hakkim L, Sathishkumar F, Sathishkumar R. Antioxidant activity of Withania somnifera (L.) Dunal by different solvent extraction methods. J Pharm Res 2011;4(5):1428-30.

27. Awah FM, Tufon E, Uzoegwu PN. Free radical scavenging activity and phenolic contents of Anthocleista djalonensis (Loganiaceae) leaf extract. Int J Biol Chem Sci 2010;4(6):2314-23.

28. Ozsoy N, Can A, Yanardag R, Akev N. Antioxidant activity of Smilax excelsa L. leaf extracts. Food Chem 2008;110:571-83

29. Pant N, Misra H, Jain DC. Phytochemical investigation of ethyl acetate extract from Curcuma aromatica Salisb. rhizomes. Arabian J Chem 2013;6:279-83.

30. Karmakar I, Dolai N, Saha P, Sarkar N, Bala A, Haldar PK. Scavenging activity of Curcuma caesia rhizome against reactive oxygen and nitrogen species. Orient Pharm Exp Med 2011;11(4):221-8. 